\title{
The severe asthma registries: a way to better know and fight the disease
}

\author{
${ }^{1}$ Pulmonary Environmental Epidemiology Unit, Institute of Clinical Physiology (IFC), National Research Council, Pisa, Italy \\ ${ }^{2}$ SOS Allergy and Immunology, USL Toscana Centro, Prato, Italy \\ ${ }^{3}$ Institute for Research and Biomedical Innovation (IRIB), National Research Council, Palermo, Italy
}

\section{Doi}

10.23822/EurAnnACI.1764-1489.203

Asthma is a heterogeneous disease, generally characterized by chronic inflammation. Severe asthma (SA) affects $5-10 \%$ of the asthma population, with the highest values in adolescents (1). The Global Burden of Disease study reported 495,000 asthma deaths worldwide in 2017 (2). In Europe, the mortality rate from asthma can vary according to the disease severity, reaching values of 11.3-14.8/1000 person-years in severe asthmatics (3). According to the European Lung White Book, annual direct costs for asthma (i.e., due to treatment) and indirect costs (i.e., due to the worsening of the quality of life and work disability) were 19.5 billion and 14.4 billion euros at European level in 2011. Individual total annual cost for asthma was $€ 3400$ (4), with about $50 \%$ due to SA or difficult to treat asthma $(1,5)$.

The interest of the international scientific community towards SA has increased in the last decades due to its high burden in terms of direct and indirect costs; moreover, there is the need to better understand the mechanisms underlying the severity of asthma and resistance to therapy through a better characterization of the disease itself (6).

Many countries have developed regional and/or national disease registries providing valuable information on country-specific epidemiological patterns, natural history, progression, impact and therapeutic risks and benefits (1).

In 2020, the International Severe Asthma Registry (ISAR) was established, as the first global registry for $\mathrm{SA}$ in adults. It is a joint initiative where national registries retain ownership of the data, sharing data in ISAR for research purposes. Its strength comes from the collection of patient-level, anonymous, longitudinal, real, standardized and high-quality data from countries around the world, with the aim of assessing existing knowledge, generating new knowledge and identifying gaps to be filled, thus promoting new lines of research (1). ISAR currently contains data on more than 10000 patients from over 24 countries, including Italy.
In Italy, since 2010 registries and initiatives for the monitoring of SA have been developed such as the Italian Registry for severe/uncontrolled asthma (RitA) (7), the Italian network for severe asthma (SANI) (8), the Italian Registry on Severe Asthma (IRSA) (9) and the Italian Network on Pediatric Severe Asthma (IPSAN) (10). Briefly, the RitA Registry was implemented within the AGAVE ("Severe Asthma: epidemiological and clinical cohorts follow up by registry and questionnaires; therapeutic appropriateness and outcome assessment, according to GINA guidelines") project (2010-2014), funded by AIFA (Agenzia Italiana del Farmaco, the Italian drugs agency) in order to assess the feasibility and usefulness of a SA registry in Italy. It is to point out that the study was carried out when Omalizumab was the only available biological drug for asthma treatment. The aim was to evaluate the appropriateness of different therapeutic strategies and to obtain longitudinal information on subjects with SA and uncontrolled asthma, selected from general and clinical populations (children and adults) at national level. The first published results regarded 493 clinical patients (7). Data about follow-up will be soon available. More recently, results about the longitudinal asthma patterns in 452 subjects from the general population sample were published (12). SANI was established in 2017 and it currently consists of 64 clinical centers spread throughout the country. This project is supported by the Global Initiative for Asthma (GINA), the Italian Society of Allergy, Asthma and Clinical Immunology (SIAAIC), the Italian Society of Pneumology (SIP / IRS) and the FederAsma e Allergie Onlus - Italian Patients Federation. SANI also collaborates with the European SHARP and global ISAR projects. The goal of the network is to create an observatory for the monitoring of SA in patients over 12 years of age. Particular attention is paid to the follow-up of patients in order to assess the natural history of the disease, the cost/benefit of new biological products, the adherence to therapy and the presence of particular disease biomarkers (8). 698 patients were enrolled by March 2019 (11). 
Bilò et al. published in this issue of the Journal the findings about the most recent and currently largest registry in Italy, the IRSA (9). IRSA was implemented in 2017 and supported by the Italian Association of Hospital Pulmonologists (AIPO) and by the Italian Association of Hospital and Territorial Allergists and Immunologists (AAIITO). IRSA aimed to collect data in SA patients ( $\geq 14$ years of age) during a 5 -years period in a real-life setting. It involves 71 Units of Allergy and Pulmonology all over the country. In particular, the registry arose from the need to understand the phenotypes of asthma refractory to standard therapies, collecting information on the epidemiological, clinical and therapeutic aspects relating to the natural course of the disease, bridging the gap between adolescents and adults (13). Comparing the data coming from these 3 Italian initiatives (table I), it clearly emerges that the descriptive characteristics of the patients are widely comparable, even if in RiTA there are more obese subjects and in IRSA more smokers. Comorbidities data are also comparable, with the exception of allergic rhinitis and atopy, more frequent in RiTA and of nasal polyps and sinusitis in IRSA. The RiTA patients appear to have less exacerbations and health services access, a lower obstructive pattern, lower FENO and $\operatorname{IgE}$ values, but higher eosinophilia values. Finally, as regard drugs, in SANI there is a higher use of oral corticosteroids and a lower use of anti-leukotrienes. The highest percentage of patients using Omalizumab was found in RiTA (64.1\%) (due to the inclusion criteria), then SANI (57\%) and IRSA (32.2\%). SANI patients were treated with Mepolizumab (11.2\%), IRSA patients with Mepolizumab (28.2\%) and Benralizumab (4.1\%). Thus, overall, the enrolled SA patients are characterized by similar features, with some variability that may be due to the different peculiarities of the involved clinical centers.

As reported by Bilò et al. (9), the presence of multiple registries at national level might be interpreted as an overlap and a limitation; on the contrary, it may represent an opportunity to increase the number of cases, widen the spectrum of information, and check their homogeneity.

Only a joint effort, also in line with what has already been done in the context of ISAR worldwide, can allow pooling the data thus covering a larger part of the national territory, with more cases, more comprehensive information and more precise estimates. Such a national collaboration would strengthen the monitoring of SA patients, leading to a better comprehension of the epidemiological, clinical, inflammatory and functional characteristics of these patients, and of the treatment efficacy (including the new biological drugs), in order to effectively counteract SA with its elevated socio-economic burden.

Table I - Comparison among patients' characteristics of IRSA (9) registry, SANI network (8) and RiTA registry (7).

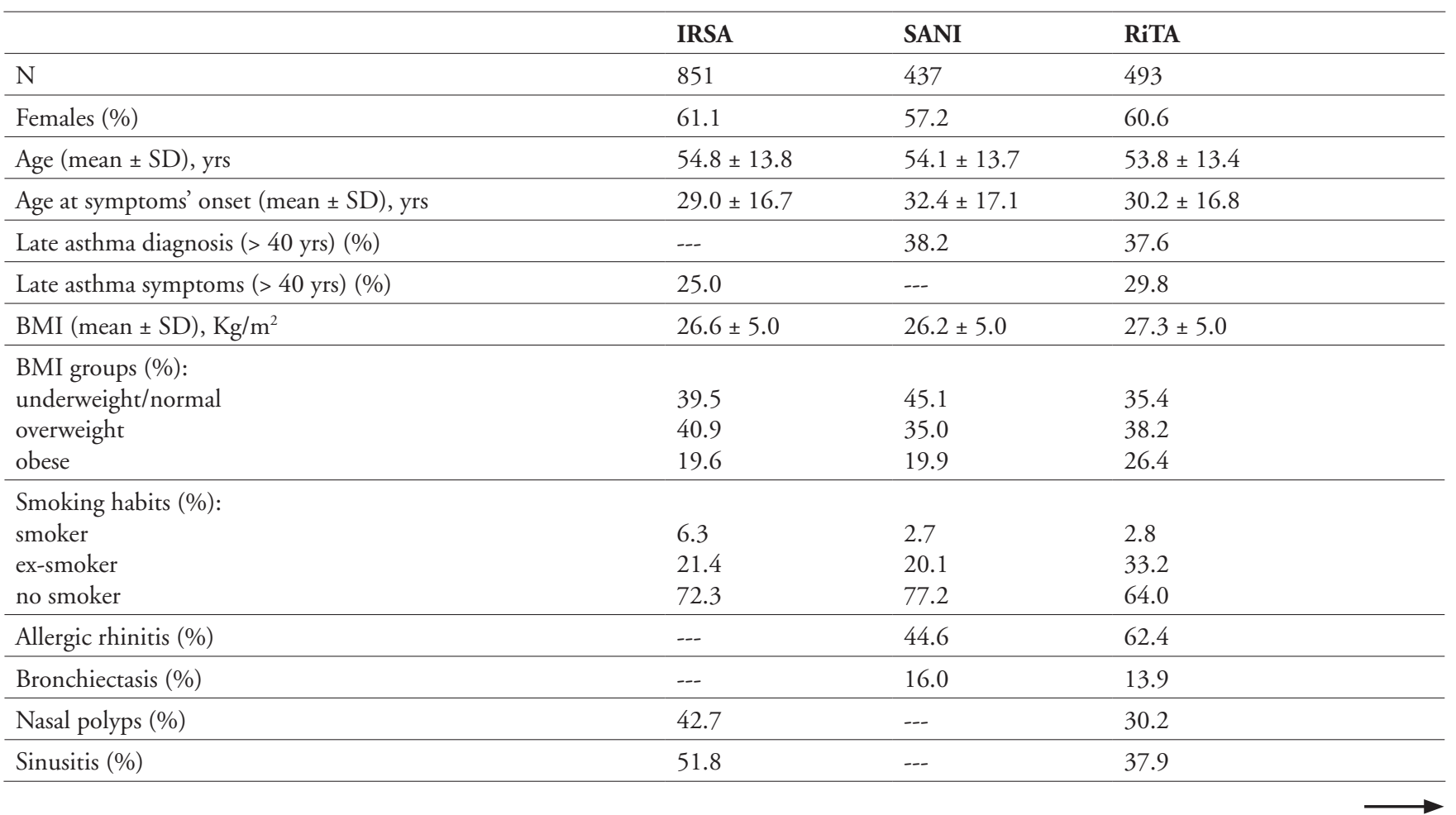




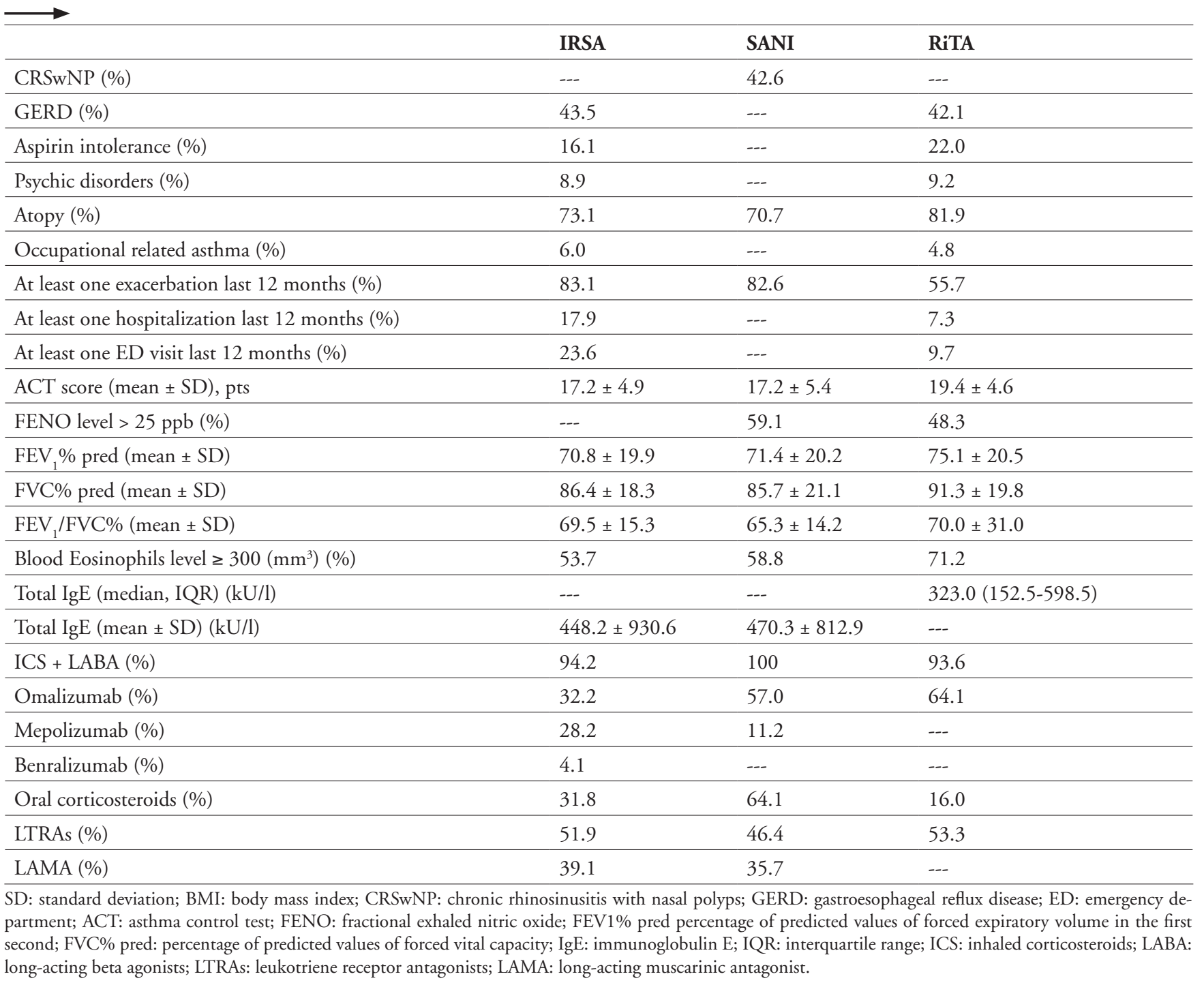

\section{References}

1. ISAR Study group. International Severe Asthma Registry: Mission Statement. Chest 2020;157:805-14.

2. GBD 2017 Causes of Death Collaborators. Global, regional, and national age-sex-specific mortality for 282 causes of death in 195 countries and territories, 1980-2017: a systematic analysis for the Global Burden of Disease Study 2017. Lancet 2018;392(10159):1736-88.

3. Engelkes M, de Ridder MA, Svensson E, et al. Multinational cohort study of mortality in patients with asthma and severe asthma. Respir Med 2020;165:105919.

4. Gibson GJ, Loddenkemper R, Sibille Y, Lundbäck B. The European Lung White Book. Respiratory health and disease in Europe. Sheffield: European Respiratory Society, 2013.

5. Zeiger RS, Schatz M, Dalal AA, et al. Utilization and costs of severe uncontrolled asthma in a managed-care setting. J Allergy Clin Immunol Pract 2016;4:120-9.
6. Wenzel S. Severe asthma: from characteristics to phenotypes to endotypes. Clin Exp Allergy 2012;42: 650-8.

7. Maio S, Baldacci S, Bresciani M, et al. AGAVE group. RItA: The Italian severe/uncontrolled asthma registry. Allergy 2018;73:683-95.

8. Heffler E, Blasi F, Latorre M, et al. SANI Network. The Severe Asthma Network in Italy: Findings and Perspectives. J Allergy Clin Immunol Pract 2019;7:1462-68.

9. Bilò MB, Antonicelli L, Carone M, et al. Severe Asthma Management in the Era of Biologics: Insights of the Italian Registry on Severe Asthma (IRSA). Eur Ann Allergy Clin Immunol 2021;53(3):103-12. Online version: Eur Ann Allergy Clin Immunol 2021;53(3):103-14.

10. Montella S, Baraldi E, Cazzato S, et al. Italian Pediatric Severe Asthma Network (IPSAN) on behalf of the Italian Society of Pedi- 
atric Respiratory Diseases (SIMRI). Severe asthma features in children: a case-control online survey. Ital J Pediatr 2016;42:9.

11. Puggioni F, Brussino L, Canonica GW, et al. Severe Asthma Network in Italy (SANI) group. Frequency of Tiotropium Bromide Use and Clinical Features of Patients with Severe Asthma in a Real-Life Setting: Data from the Severe Asthma Network in Italy (SANI) Registry. J Asthma Allergy 2020;13:599-604.
12. Maio S, Baldacci S, Simoni M, et al. On Behalf Of The Agave Pisa Group. Longitudinal Asthma Patterns in Italian Adult General Population Samples: Host and Environmental Risk Factors. J Clin Med 2020;9(11):3632.

13. Micheletto C, Bilò MB, Antonicelli L, et al. IRSA. Severe asthma in adolescents and adults: a national, multicenter registry in real life. Eur Ann Allergy Clin Immunol 2018;50:196-201. 